\title{
Determination of Physical Property Lower Limits of Chang 6 Effective Reservoir in Tangjiaping Area, Ordos Basin
}

\author{
Li Chan \\ Ganguyi Oil Production Plant, Yanchang Oilfield Company Limited 54207848@qq.com
}

Key words: Reservoir space, Physical property lower limit, Chang 6 oil-bearing formation, Tangjiaping area

Abstract: Arkose has been designated as the main reservoir of Chang 6 oil-bearing formation in Tangjiaping area and has a good development of residual inter-granular pores and dissolved pores. The porosity of Chang 6 reservoir mainly ranges from $5 \%$ to $12 \%$ and the average is $9.2 \%$, while the permeability is mostly less than $1 \times 10^{-3} \mu \mathrm{m}^{2}$ and the average is $0.85 \times 10^{-3} \mu \mathrm{m}^{2}$, and belongs to typical tight reservoir. With integrated analysis of four methods, the physical property lower limits of Chang 6 tight reservoir have been determined: the porosity is $8 \%$, permeability is $0.2 \times 10^{-3} \mu \mathrm{m}^{2}$ and oil saturation is $42 \%$, all of which can be used to calculate the reserves of tight reservoir.

\section{INTRODUCTION}

Chang 6 tight reservoir in Ordos Basin is featured by multiple genetic types of sand body, complicated diagenesis as well as anisotropy, which brings about many challenges to the calculation of tight oil reserves, but the determination of effective reservoir is one of the key techniques of dividing oil-bearing boundaries of tight oil. Core, slice, mud logging, well logging and oil testing data are generally used to determine the physical property lower limits of effective reservoir, specifically, on the basis of oil testing data and actually measured physical property data of core samples, the criteria of the physical property lower limits is recognized, and finally, the lower limits of effective reservoir are determined by with the integration of electric log data. Those lower limit values can be calculated on the basis of statistical method, oil testing method, irreducible water saturation method and so on. The commonly used method is based on the determination of porosity-permeability relation of sandstone with oil/gas show, or we can use physical property lower limit of oil-bearing reservoir to compensate for porosity loss if hydrocarbon reservoir is accumulated so as to calculate the lower limit of porosity. Therefore, on the basis of Chang 6 reservoir characteristics, this paper uses four methods to determine the lower limits of physical property which provides conditions for the geological reserves calculation of tight oil.

\section{GEOLOGICAL OVERVIEW}

Tangjiaping area lies in Yan'an, Shanxi province geographically and eastern part of Northern Shanxi Slope in Ordos Basin tectonically, the landform is not flat because of ridges and replats, the ground elevation ranges from $880 \mathrm{~m}$ to $1200 \mathrm{~m}$, and the area is about $120 \mathrm{~km}^{2}$. The strata of Chang 6 oil-bearing formation is relatively stable with the thickness between $90 \mathrm{~m}$ and $140 \mathrm{~m}$, it develops multiple sets of bentonites with the thickness ranges from 2 to $4 \mathrm{~m}$, and the log characteristics is obvious and easy to recognize. Chang 6 oil-bearing formation is structurally similar to Northern Shanxi slope, and belongs to low amplitude structural relief which is locally developed on the monocline structure with westward inclination.

The lake development reached the peak in Chang 7 stage, the lake water became shallow gradually in Chang 6 stage, prodelta facies and delta front underwater distributary channel facies are developed from the bottom to the top of Chang 6 strata. Chang 6 sand body is featured by lenticular type of "down convex and up flat" with multiple single sand bodies cutting and superposing each other, and forms irregular tabular body, there are discontinuous mudstone stripes or lens in between single sand bodies. 


\section{RESERVOIR CHARACTERISTICS}

\section{RESERVOIR LITHOLOGY}

According to the identification results of 24 slices of Chang 6 oil-bearing formation in Tangjiaping area, the rock type is relatively simple and mainly arkose. Among which, feldspar content of the arkose ranges from $46.1 \%$ to $58.8 \%$ and the average is $53.88 \%$, quartz content ranges from $15.3 \%$ to $31.8 \%$ and the average is $23.52 \%$. Biotite content changes from $2.4 \%$ to $18.6 \%$ and the average is $9.04 \%$, the content of lithic fragment is relatively less, it changes from $2 \%$ to $4 \%$ and the average is $3 \%$.

\section{RESERVOIR SPACE}

According to the analysis of slice and SEM, the main storage space of Chang 6 reservoir is inter-granular pores, dissolved pores and micro-fractures (Fig.1). The surface porosity content changes from $6.2 \%$ to $8.1 \%$ and the average is $6.9 \%$. Among which, the residual inter-granular pore is the main pore type, it accounts for $30 \%$ to $65 \%$ of the total pore and the average content is about $43.08 \%$. The dissolved pore contains inter-granular and intra-granular dissolved pore, its content ranges from $15 \%$ to $42 \%$ and the average is $29.81 \%$. Micro-fracture is less developed and only accounts for about $5 \%$. Besides, intra-crystalline pore of clay mineral also occupies $12 \%$ of the total pores which can reach a maximum of $20 \%$, and it is generally occupied by irreducible water.

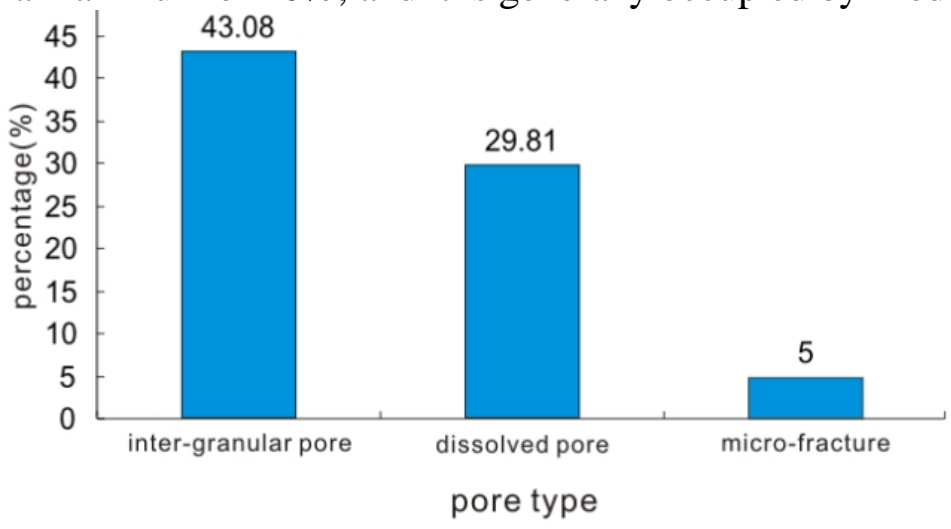

Fig.1 Reservoir space characteristics of Chang 6 reservoir in Tangjiaping area

\section{PHYSICAL PROPERTY CHARACTERISTICS}

According to statistics of 273 pieces of core data analysis for 12 wells in Tangjiaping area, the reservoir porosity mainly ranges from $5 \%$ to $12 \%$ and the average is $9.2 \%$. The permeability is mainly less than $1.0 \times 10^{-3} \mu \mathrm{m}^{2}$ and the average is $0.85 \times 10^{-3} \mu \mathrm{m}^{2}$ and accounts for $80 \%$ of the samples, it is obvious that the reservoir belongs to typical tight reservoir.

\section{DETERMINATION OF EFFECTIVE RESERVOIR LOWER LIMIT}

According to conventional logging, testing, physical property analysis, mercury injection and relative permeability data, the effective thickness lower limit of Chang 6 tight reservoir is determined by use of loss rate method, empirical statistics method, cross plot method, Walsh method, capillary pressure curve method and relative permeability experimental method, and finally determine the physical property lower limits of Chang 6 effective reservoir.

\section{WALSH METHOD}

The macroscopic porosity and permeability characteristics are the reflection of microscopic pore structure and throat size of the rock. The minimum pore channel in which can accumulate oil/gas and make it permeate is called minimum flow pore-throat radius. The capillary pressure testing data is used to analyze the structure of rock microscopic pore-throat so as to determine the minimum flow pore-throat radius, establish the relations between pore-throat radius and conventionally analyzed 
porosity and permeability, and calculate the porosity and permeability under the minimum flow pore-throat radius, so the physical property lower limits of effective reservoir are determined. The minimum flow pore radius is calculated through Walsh formula, specifically, on the basis of equal-porosity volume increment, the permeability contributions and accumulative infiltration capacity are calculated in every interval of pore volume, the Walsh formula is:

$$
\begin{aligned}
& \Delta K_{i}=\left[\left(2^{i}-1\right) r_{i}^{2} / \sum\left(\left(2^{i}-1\right) r_{i}^{2}\right)\right] \times 100 \\
& \sum K=\sum \Delta K_{i}
\end{aligned}
$$

$\Delta \mathrm{K}_{\mathrm{i}}$ : interval infiltration capacity contributions, \%

$\sum \mathrm{K}$ : accumulative infiltration capacity, \%

I: interval serial number of equal-porosity volume increment

$r_{i}$ : relevant pore radius, $\mu \mathrm{m}$.

The minimum flow pore-throat radius of Chang 6 reservoir calculated by Walsh method is $0.177 \mu \mathrm{m}$. The integration of the minimum flow pore-throat radius with the relation between core porosity and permeability can determine the lower limit of permeability to be $0.191 \times 10^{-3} \mu \mathrm{m}^{2}$ and relevant porosity to be $7.8 \%$ (Fig.2, Fig.3).

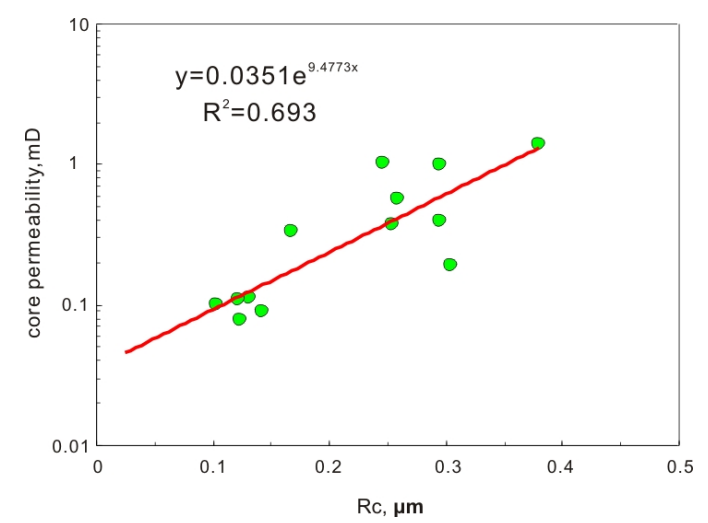

Fig. 2 The cross plot between the minimum flow pore-throat radius and permeability

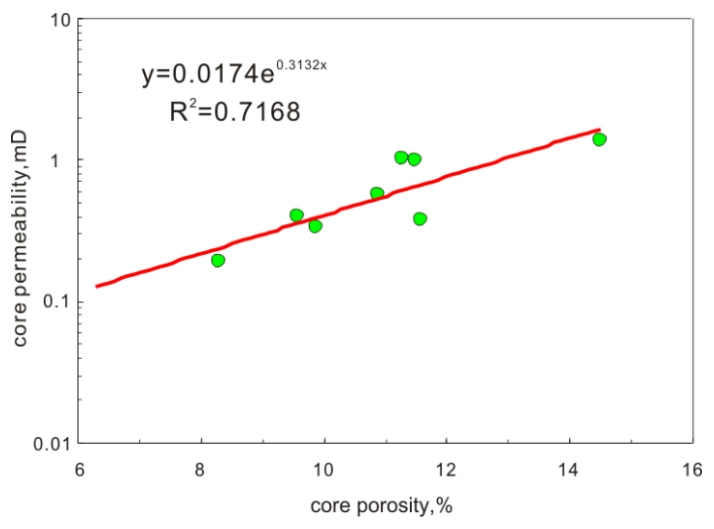

Fig3 The cross plot between core porosity and permeability

\section{CAPILLARY PRESSURE CURVE METHOD}

The core capillary pressure curve data obtained by mercury injection test is effective to reflect the pore structure of reservoir rock. Reservoir porosity and permeability are the macroscopic parameters of reflecting its pore structure, therefore, rock porosity and permeability are closely correlated to the relevant pore structure parameters so as to determine the displacement pressure and relevant physical property lower limit of reservoir rock.

The determination of physical property lower limit of Chang 6 reservoir includes two ways: displacement pressure method and medium radius method.

\section{1) Displacement pressure method}

According to the cross relation between displacement pressure and rock permeability of Chang 6 reservoir (Fig.4), if permeability is less than $0.2 \times 10^{-3} \mu \mathrm{m}^{2}$, the displacement pressure is relatively high and increases fast with the decrease of porosity. But if permeability is larger than $0.2 \times 10^{-3} \mu \mathrm{m}^{2}$, the displacement pressure obviously decreases and has a little change. Therefore, the permeability lower limit can be defined as $0.2 \times 10^{-3} \mu \mathrm{m}^{2}$. With the integration of the correspondent porosity and permeability cross plot of mercury injection test (Fig.5), the lower limit of permeability is determined to be $0.2 \times 10^{-3} \mu \mathrm{m}^{2}$ and relevant porosity is $8 \%$. 


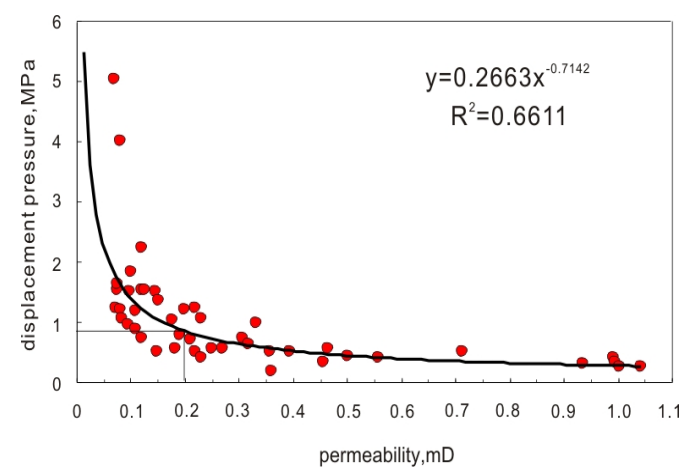

Fig.4 The relation graph between displacement pressure and permeability of Chang 6 reservoir

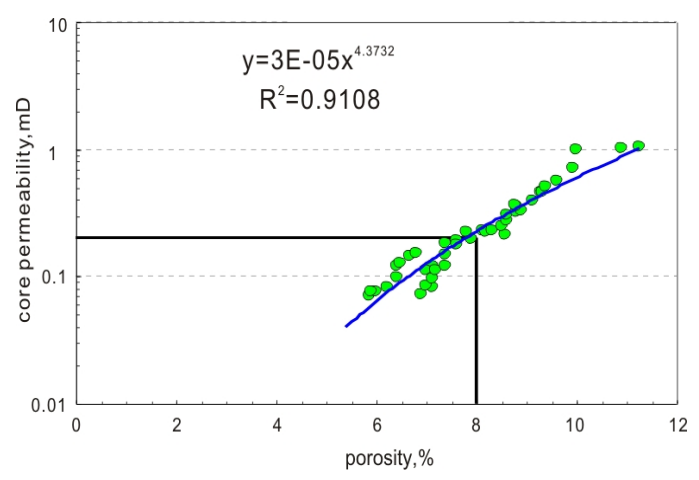

Fig. 5 The cross plot between core porosity and permeability of mercury injection of Chang 6 reservoir

\section{2) Medium pressure method}

In mercury injection capillary pressure curve, medium pressure is the mercury injection pressure when mercury saturation equals $50 \%$. If permeability is less than $0.2 \times 10^{-3} \mu \mathrm{m}^{2}$, permeability relatively increases fast with the decrease of medium pressure, but if permeability is larger than $0.2 \times 10^{-3} \mu \mathrm{m}^{2}$, permeability relatively increases slowly with the decrease of medium pressure (Fig.6). Therefore, the relevant lower limit of permeability and porosity is thought to be $0.2 \times 10^{-3} \mu \mathrm{m}^{2}$ and $8 \%$, respectively.

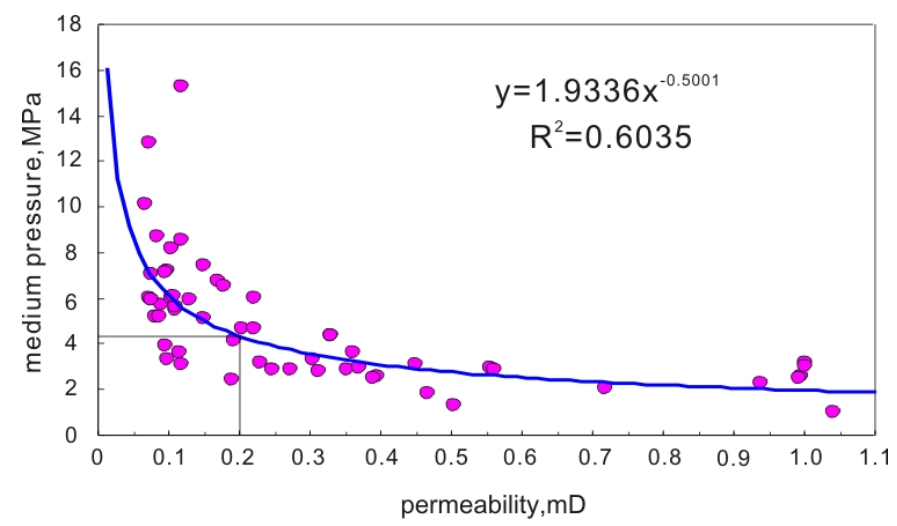

Fig.6 The relation graph between medium pressure and permeability of Chang 6 reservoir

\section{CROSS PLOT METHOD}

Oil testing data is visual to accurately determine reservoir-produced flow property and the lower limit criteria of reservoir effective thickness. The cross plot chart of the relation between reservoir porosity and deep resistivity and the relation between porosity and water saturation can be established on the basis of oil testing data so as to determine the lower limit of reservoir-produced flow.

According to the cross relation analysis of porosity-resistivity of Chang 6 reservoir oil testing layer (Fig.7), the porosity is obviously larger than that of dry layer and is split at $7.95 \%$. The lower graph shows that the water saturation boundary of oil and water layer is 58\% (Fig.8). The water saturation of oil layer is obviously less than $58 \%$, the water saturation larger than $58 \%$ is pure water layer, so the upper limit of oil layer water saturation of Chang 6 effective reservoir is $58 \%$ and the porosity lower limit is $7.95 \%$.

\section{RELATIVE PERMEABILITY EXPERIMENTAL METHOD}

According to the experimental analysis of oil-water relative permeability with steady-phase method for 4 pieces of core samples in Chang 6 reservoir, if water saturation is less than 57\%, the correspondent relative permeability of oil phase is larger than that of water phase, indicating that reservoir-produced flow is mainly oil of non-wetting phase without producing any water, so the oil saturation lower limit of Chang 6 reservoir can be determined to be $42 \%$. 
According to different ways, the physical property lower limits of Chang 6 effective reservoir in Tangjiehe area can be determined: the porosity is $8 \%$, permeability is $0.2 \times 10^{-3} \mu \mathrm{m}^{2}$ and oil saturation is $42 \%$.

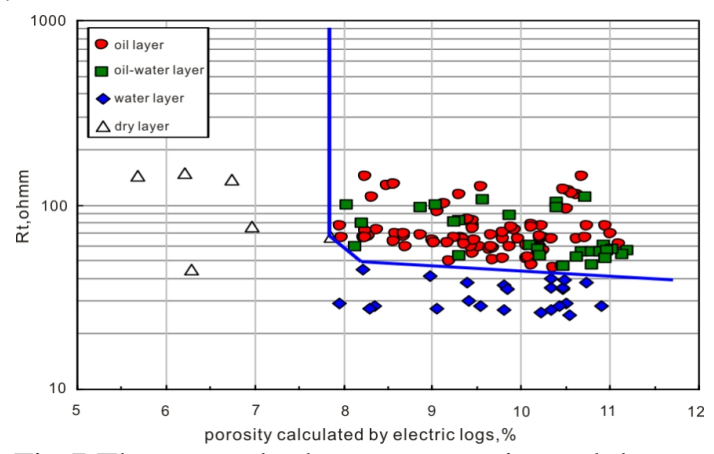

Fig.7 The cross plot between porosity and deep resistivity of Chang 6 reservoir

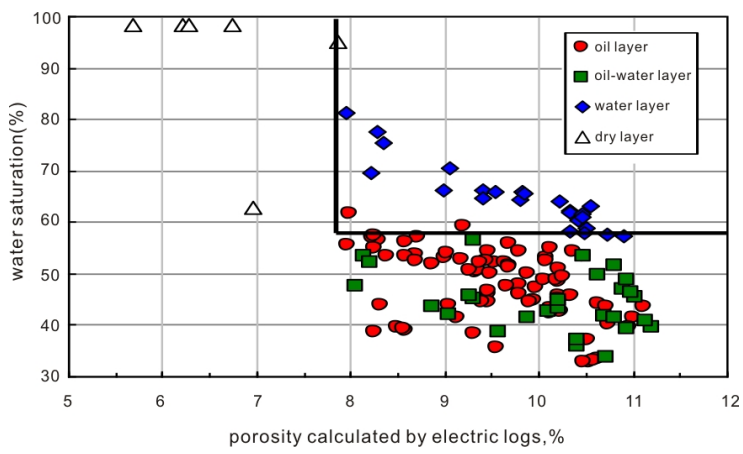

Fig. 8 The cross plot between porosity and water saturation of Chang 6 reservoir

\section{CONCLUSION}

1) Arkose has been designated as the main reservoir of Chang 6 oil-bearing formation in Tangjiaping area and has a good development of residual inter-granular pores and dissolved pores. The porosity of Chang 6 reservoir mainly ranges from $5 \%$ to $12 \%$ and the average is $9.2 \%$, while the permeability is mostly less than $1 \times 10^{-3} \mu \mathrm{m}^{2}$ and the average is $0.85 \times 10^{-3} \mu \mathrm{m}^{2}$, and belongs to typical tight reservoir.

2) With integrated analysis of four methods, the physical property lower limits of Chang 6 tight reservoir have been determined: the porosity is $8 \%$, permeability is $0.2 \times 10^{-3} \mu \mathrm{m}^{2}$ and oil saturation is $42 \%$.

\section{REFERENCES CITED}

[1] Peng, B., and G. X. Lv, 2008, Research on low porosity and permeability of sandstone oil/gas reservoir performance in lower Permian Shanxi Formation of Zizhou Gas Field, Journal of Petroleum Geophysics, v. 6, p. 11-13.

[2] Wang, Y. Z., Y. C. Cao, and G. Q. Song, 2009, Determination of physical property lower limit of deep clastic effective reservoirs of Paleogene in Dongying Depression, Journal of China University of Petroleum: Edition of Natural Science, v. 33, part 4, p. 16-21.

[3] Li, W. H., Z. H. Zhang, and Z. L. Zan, 2012, Lower limits of physical properties and their controlling factors of effective coarse-grained clastic reservoirs in the Shahejie Formation on northern steep slope of Bonan Subsag, Bohai Bay Basin, Journal of Oil and Gas Geology, v. 33, part 5, p. 767-775.

[4] Shao, C. X., Y. Z. Wang, and Y. C. Cao, 2008, Two new methods used to determine the low limits of effective reservoir physical properties and their applications-a case study on deep clastic reservoir of Palaeogene in Dongying Depression, Journal of Oil and Gas Technology (Journal of Jianghan Petroleum Institute), v. 30, part 2, p. 414-416.

[5] Gao, G., X. Shen, and Y. L. Han, 2010, The lowest limit of physical property in sandstone conducting system and their effects on oil accumulation with low porosity and permeability-a case study of Chang (4+5) and Chang 6 in Hujianshan area, Ordos Basin, Journal of China University of Petroleum: Edition of Natural Science, v. 16, part 3, p. 351-357.

[6] Pang, G. F., Z. Liu, and S. Zhao, 2011, The study on lower limit of porosity for Chang 8 oil accumulation in Zhengjing area, Ordos Basin, Journal of Geosciences, v. 25, part 2, p. 271-279.

[7] Jia, C. Z., C. N. Zou, and J. Z. Li, 2012, Assessment criteria, main types, basic features and resource prospect of the tight oil in China, Journal of Acta Petrolei Sinica, v. 33, part 3, p. 343-350. 